\title{
Modelling Technology for Building Fire Scene with Virtual Geographic Environment
}

\author{
Yiquan Song ${ }^{\mathrm{a}}{ }^{*}$, Liy ang $\mathrm{Zhao}^{\mathrm{a}}$, Min $\mathrm{Wei}^{\mathrm{a}}$, Hongxin Zhang ${ }^{\mathrm{a}}$, Wei Liu ${ }^{\mathrm{a}}$ \\ ${ }^{a}$ College of Geography and Environmental Science, Tianjin Normal University, Tianjin 300387, syiq@ hotmail.com
}

KEY WORDS: Building Fire Scene, Virtual Geographic Environment, Building Fire Simulation and Analysis, Emergency Management, Indoor

\begin{abstract}
ABS TRACT:
Building fire is a risky activity that can lead to disaster and massive destruction. The management and disposal of building fire has always attracted much interest from researchers. Integrated Virtual Geographic Environment (VGE) is a good choice for building fire safety management and emergency decisions, in which a more real and rich fire process can be computed and obtained dynamically, and the results of fire simulations and analyses can be much more accurate as well. To modelling building fire scene with VGE, the application requirements and modelling objective of building fire scene were analysed in this paper. Then, the four core elements of modelling building fire scene (the building space environment, the fire event, the indoor Fire Extinguishing System (FES) and the indoor crowd) were implemented, and the relationship between the elements was discussed also. Finally, with the theory and framework of VGE, the technology of building fire scene system with VGE was designed within the data environment, the model environment, the expression environment, and the collaborative environment as well. The functions and key techniques in each environment are also analysed, which may provide a reference for further development and other research on VGE.
\end{abstract}

\section{INTRODUCTION}

Fire is one of the most frequent and devastating disasters, and the frequency of fire is the highest among all kinds of disasters. Furthermore, building fire accounts for more than $80 \%$ of fire accidents. To understand building fire prevention management, intelligent analyses and rapid disposal have become important topics for urban emergency management.

To improve the emergency response capability of building fire, many researchers have examined the mechanism of building fire occurrence, spread and extinction (Stollard, 2014; Hasofer, 2006). The evolutionary law of building fire event has been preliminary mastered, and several building fire models consistent with reality have been constructed (Mcgrattan, 2013). All current research methods rely on computer based building fire simulations and analysis. With computer simulations, the evolutionary process of building fire can be modelled and expressed dy namically, and the evolution of building fire can thus be predicted. Computer simulations can also provide scientific, efficient and orderly reference for emergency decisionmaking as well as improve the response levels to building fires with important scientific value and application significance. Although many achievements have been made regarding building fire model, most research focuses on the fire mechanism model, which is inadequate to express and analyse the building space environment. In this context, many researchers have begun to research the combination way of building fire and building environment model (Tang, 2012; Isikdag, 2008). Of these approaches, building space model mostly adopts Geographic Information System (GIS) technology. However, at present, this combination mostly focuses on the two-dimensional (2D) space, and studies on the combination of the fire model and the spatial information in the three-dimensional (3D) space are relatively few. Furthermore, building fire analyses cannot be separated from indoor crowds, which is another important element of building fire scene. How to realize the intelligent crowd evacuation is always a focus of building fire model (Shi, 2009; Tang, 2008). Thus, to modelling a building fire, the fire event, the indoor crowd and the building space environment must be considered all. In short, to modelling the building fire more intelligent, all the elements relate to building fire (e.g., building space environment, indoor crowds) must be considered, and to analysis the characteristics of each element elaborately, and to modelling all the elements unified. Only this, a more intelligent analy sis and decision support for building fire can be provided.

Based on geographic information, remote sensing information, cyberspace information and mobile spatial information, Virtual Geographic Environment (VGE) is an important research direction of GIS to study the phenomena and regularities of the realistic geographical environment and cyberspace (Lin, 2013; Lin, 2005; L., 2011). Virtual Reality (VR) is the core of VGE. At present, VGE has been widely used in air pollution simulation, flood simulation, emergency evacuation and other fields (Lin, 2010; Song, 2013; Li, 2015). Based on VGE, the 3D real building space environment and existing building fire model can be combined to make more accurate and abundant

* Corresponding author 
simulations and analyses of building fire. More effective emergency decision support for building fire management and the formulation of emergency plans can also be provided as a result. In this context, modelling technology of building fire scene with VGE was researched in this paper, which to enhance the emergency response capabilities of building fire.

\section{MODELLING ELEMENTS OF BUILDING FIRE SCENE}

Fire scene is the spatial environment where related to the process of fire occurrence and development. And building fire scene is the fire scene in building. To provide an intelligent decision support, four interrelated elements should be considered for building fire, which including building space environment, fire event, indoor Fire Extinguishing System (FES) and indoor crowd.

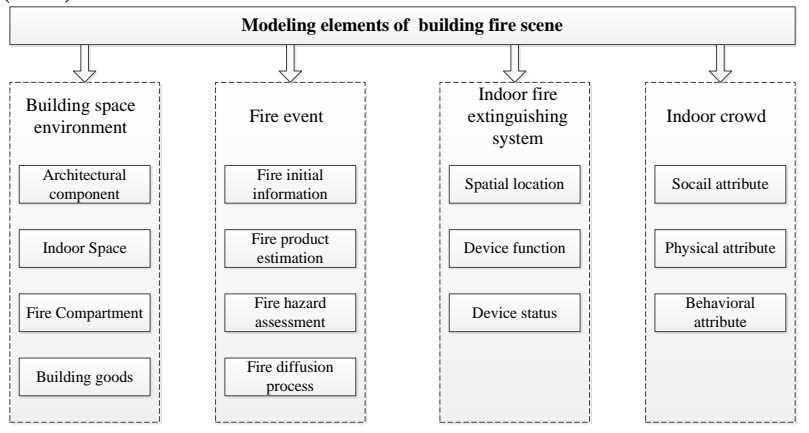

Figure 1. Modelling elements of a building fire scene

\subsection{Building space environment}

Building space environment is the spatial formation of a building, and it is the spatial basis to modelling other modelling elements in building fire scene. It is important and difficult to model and express the building space environment accurately under the analyse requirement of building fire scene. However, the complex features of building (multi-lay er and multi-use) increase the difficulty of modelling it.

To modelling a building fire scene, building space environment should describe the information related to architectural component, indoor space, fire compartment and the goods in the building. Architectural component are the features of formation building, which maybe a wall, a beam, a column or a window. Architectural component information includes material, fire resistance and so on. Architectural component can provide basic information for building fire spread compute. Indoor space is a space within building and with unique sematic information, which is composed of various architectural components. It may be a room, a corridor, a staircase, or a hall. Indoor space can provide the basis for the fire disaster assessment and crowd evacuation path searching. A fire compartment is an enclosed space in a building with fire-resistant architectural components (e.g., firewalls) which can hinders the spread of fire. Based on fire compartment, the building fire event can be analysed by each fire compartment, which can provide more smart support for fire simulation and analyses. The building goods refer to the furniture or decorations in building. For the low ignition points of building goods, the fire area may be enlarge when the fire contact with building goods, and intensified the loss of building fire.

\subsection{Fire event}

Fire is a disaster that is out of control in time and space. Fire event is the main factors causing smoke flow and the damage of architectural component, and it is the dominant factor in the formation of building fire scene.

The occurrence and development of building fire is a complicated physical and chemical process. It contains turbulent flow and turbulent mixing, heat and mass transfer, pyrolysis and various chemical reactions (Stollard, 2014; Hasofer, 2006). Furthermore, a fire event involves the interaction of these processes. The diversity of building materials increases the difficulty of building fire modelling. To describe a fire event, the initial information and the combustion products of the fire must be included. The initial fire information is the initial fire position, burning objects, and other information of a fire. The fire combustion products are the key points to evaluate fire hazards for crowd. According to the spatialtemporal distribution of smoke, temperature, toxic gas (e.g., $\mathrm{CO}, \mathrm{CO}_{2}$.), indoor crowd injuries can be evaluated with building fire hazard model (Hartzell, 1988; Stec, 2011). Building fire model needs to describe the process of occurrence and development of fires and needs to calculate its harm to architectural component and indoor crowd. The basic theories of building fire model are the chemical and physical fundamentals of the combustion process, the fire dynamics mechanism and the fire smoke mechanism (Stollard, 2014). At present, the numerical simulation, which was with mathematical methods and based on computer, has become the main way to model fire event.

\subsection{Indoor FES}

Indoor FES is a safety management system which is used to extinguish or prevent the spread of fire in the building. Indoor FES is important to the safety of building and indoor crowds, and it has become an essential part of modern architecture.

The composition of indoor FES is complex, the type of it was numerous, and the function of it was varied. A common indoor FES include automatic sprinkler system, automatic fire alarm system, smoke control system, fire water supply system, gas extinguishing system, fire hydrant system, fire extinguishers, emergency lighting system, evacuation instructions, fire doors, fire shutter, etc. The diversity of indoor FES makes it difficult to describe or modelling unified. To describe an indoor FES, it is necessary to describe the space location and function of each subsystem of it. The running state of FESs is dynamic. And it may start only in the case of fire. Therefore, to modelling a FES needs to describe its action (such as the opening and closing state of a fire sprinkler system). In addition, the main function of FES is fire extinguishing. Therefore, indoor FES modelling is often combined with fire event to form a fire process model. 


\subsection{Indoor crowd}

Indoor crowd are the human during building fire process, and it is the most important object in the building fire scene. The primary goal of building fire management is to ensure crowd safety and provide an optimal evacuation path for crowd.

Human are advanced organisms with intelligent perception and self-determination. And to model or to describe human accurate is difficult. The information to describe a human can be divided into the following three parts: physical attributes, behavioural attributes and social attributes. Human physical attributes include the spatial location, gender, age, weight, maximum travel speed, etc. of a human. Human behavioural attributes are response time, reactions to fire emergencies and so on. Human social attributes are the description of social relation between the individuals. Crowd model was the focus of computer science and sociology always, and many models have been proposed and applied. The focus of crowd model is to express the human behaviour (e.g., finding paths, avoiding obstacles, and dealing with panic) natural and accurate.

\section{FRAMEWORK OF THE BUILDING FIRE S CENE VGE SYSTEM}

Different from the GIS, the construction of a VGE system involves a large number of models, and decision support function is more emphasized also. A VGE system usually divided into four parts: data environment, model environment, expression environment and collaborative environment (L. 2011). Therefore, building fire scene VGE system can be divided into these four environments as well.

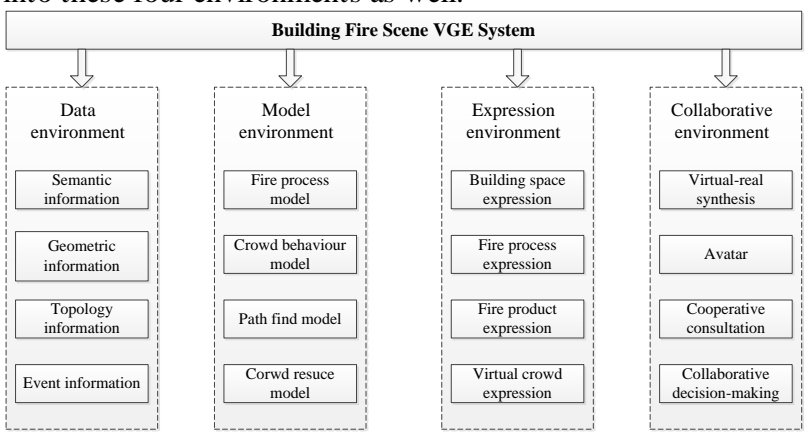

Figure 2. Framework of building fire scene VGE sy stem

\subsection{Data environment}

Based on the data acquired, the key of data environment in building fire scene VGE system was to research the semantic division method and the spatial expression method of building fire scene, and build 3D spatiotemporal data model in the end contains semantic, geometry, topology and event information. With data environment, the elements in building fire scene (e.g., space environment, indoor FES) can be modelled unified.

At present, much data of building fire scene can be obtained, and part of data can be acquired near real time. For building spatial data, LiDAR (Light Detection and Ranging) was widely used in indoor spatial data acquisition, and the resolution of data obtained can be reached decimetre level (Hong, 2013). For environment parameters of the building fire scene, with Wireless Sensor Network (WSN) (e.g., smoke sensor, temperature sensor) assembled in building, the fire situation can be perceived dynamically. For indoor crowd data, the geolocation of individual position can be obtained with Indoor Positioning System (IPS) (e.g., WIFI, Bluetooth, geomagnetism), and the accuracy of data can be reached metre level (Liu, 2016). All above data acquisition technologies make a basis for data environment in building fire scene.

Preliminary study on data environment in building fire scene had been carried out. And the building spatial environment is a research emphasis. In GIS field, with attention paid to the micro-geographical environment (Song, 2013), Open Geospatial Consortium (OGC) has formulated City Geography Markup Language (City GML) and Indoor Geography Markup Language (IndoorGML) specification (Kim, 2014; Gunduz, 2016) . The building environment in CityGML was focuses on the space composition of it (e.g., room, openings, building parts), architectural component and fire compartment was not defined, which make it difficult to given a unified description for the whole building fire scene. On the basis of CityGML, IndoorGML was focuses on the way of modelling indoor spaces for navigation purposes (Kim, 2014). However, IndoorGML is difficult to reflect the spatial accessibility changing with fire event still, and the shortest path obtained with IndoorGML was static and not suited for building fire scene. Therefore, both CityGML and IndoorGML in GIS field cannot meet the requirement of data environment. In construction industry, Industry Foundation Classes (IFC) and Building Information Model (BIM) has been applied in building fire research also (Spearpoint, 2007; Dimy adi, 2008; Wang, 2014). However, IFC model was focuses on the information representation of architectural components, and the indoor space division was lacked, which is inadequate for building fire scene modelling also. Many scholars have begun to study data model for building fire scene already (Zhu, 2014), but in general, the model advanced still cannot meet all the needs of data environment for building fire scene. In this context, combine GIS and related data model to design a new data environment to meet the analysis requirements of building fire scene, has become a key in building fire scene VGE system.

\subsection{Model environment}

Based on data environment, the key of model environment in building fire scene VGE system is to build a lot of model to provide support to disposal and response of building fire. Model environment is the key of building fire scene VGE system application.

The models related to building fire scene VGE system was much, fire process model, crowd behaviour model, path finding model and crowd rescue model and four typical models. Fire event and FES are both modelled in fire process model. With fire process model, the fire-affected area in different time can be obtained 
dynamically, and the temperature and smoke concentration in 3D space can be computed also (Stollard, 2014). The fire process model can provide services for crowd evacuation and building damage calculation. With crowd behaviour model, building environment can be dynamically perceived by individual, and the individual behaviours in different scenarios can be simulated, the spatiotemporal location of the individuals can be calculated dynamically, the intelligent management and decision-making of crowd evacuation can be realized finally (Shi, 2009). Based on path finding model, with model parameters (e.g. crowd spatiotemporal distribution, position and width of exits) and the modelling goals (e.g., ease congestion, reduce the total evacuation time, reduce the fire hazards to crowd), crowd evacuation paths can be calculated intelligently (Hajibabai, 2007; Song, 2016). Based on crowd rescue model, considering fire hazard on firefighters and fire damage of architectural component, the optimal rescue route can be searched to help the firefighter evacuate the trapped people (Kobes, 2010; Wu, 2012).

The common fire process models used on current are Field Model, Zone Model and Network Model (Yin, 2002; Fan, 2000; Chow, 1996). Network Model regards the whole building as a network system, each room in the building is regarded as a network node, and each node is connected by airflow paths (Fan, 2000). In Network Model, the airflow, pressure distribution and smoke propagation in the building are studied using the conservation equations of mass and energy. Zone Model divides a room into two regions, named the upper layer (hot air) and the lower layer (cold air) respectively (Chow, 1996). Zone Models also assume that the physical parameters (such as temperature and smoke concentration) in each region are uniform, and the quality and energy conservation principle and the ideal gas law calculate parameter changes. Field Model is developed on the basis of Computational Fluid Dynamics (CFD) and Computational Combustion Dy namics (CCD) (Yin, 2002). Field Model divides the indoor space into a large number of interrelated small units, which are called voxels. In each voxel, the mass equation, momentum equation and energy equation need to be solved, such as buoyancy, thermal radiation and disturbance. Each of the above three fire process model has its own advantages and disadvantages. Among them, the Field Model is more widely for the output data with high precision. The Fire Dynamics Simulator (FDS) developed by NIST is the most distinctive field model currently (Yin, 2002). Based on the FDS model, the dynamic simulation of fire processes and the accurate calculation of heat release rate, gas temperature, convection and radiation, and the concentration of gas components can be realized. However, the combination of the FDS and FES is still relatively weak now. In addition, the fire process model must integrate the data environment of building fire scene. Only with this, the accuracy of the fire simulation can be guaranteed, but very little model exists regarding in this idea.

In the aspect of crowd behaviour model, there are much models advanced and used (e.g., Threshold Model, Flocking Model, and Social Force Model) (Thalmann, 2007). Cellular Automata (CA) and Multi-agent System (MAS) are also widely used in crowd behaviour simulation (Tang, 2012; Chow, 1996). The advantage of CA modelling is that it can simulate the crowd through the simple space division and the behaviour transformation rules. While MAS has advantages over CA in expressing more types of individual behaviours, and it does not have to iterate pre-set parameters. Both CA and MAS have been applied in the simulation of crowd behaviour in building fire scene (Shi, 2009; Tang, 2008). Although many crowd behaviour models were advanced, the integration between crowd behaviour model and geospatial environment model is still relatively weak. In addition, for building fire, it is important to consider the individual dynamic perception of the fire scene, to design the diversity of individual behaviour and to realize the crowd dynamic simulation and intelligent evacuation management. These topics all require further study.

\subsection{Expression environment}

Based on the data environment and model environment, the key of expression environment in building fire scene VGE system is focus on multidimensional dy namic visualization of fire process, linkage visualization and scene navigation with avatar, multidimensional visual analysis in 3D environment, and provides support for emergency decision-making. The expression environment of building fire scenes contains three aspects in data content, building space environment visualization, fire event visualization and virtual crowd visualization. With the development of $3 \mathrm{D}$ graphics engine technology and 3D graphics algorithms (e.g., scene management algorithm, data scheduling algorithm), building space environment visualization is relatively mature. Fire event visualization and virtual crowd visualization has become the two key points of expression environment in building fire scene VGE system.

By obtaining the fire information form 3D space dynamically, the focus of the fire event visualization is to reappearance the fire process on the computer. This includes the following two aspects. One is to visualize flame spread and smoke movement natural, and the other is to visualize the fire event products (such as toxic gases or temperature fields) on demand. These two aspects are the important basis for decision-making analy ses of fire event. In aspect of visualization technology, the fire event expression requires support for 3D dynamic visualization and $2 \mathrm{D}$ slice visualization. At present, fire event visualization research has made much progress, such as visualization based on particles (Cha, 2012). NIST also developed a visualization software Smokeview (Forney, 2004), which can used to display the output of FDS and CFAST simulation. However, it is still important to consider the reliability of building fire scene and the content and efficiency of fire event representation, to design a flexible fire event visualization tool meeting the requirement of different scenarios and different applications of building fire scene researching.

At present, virtual crowd visualization technology has been applied more recently in VR and computer games (Thalmann, 2007). The researching of crowd visualization includes two 
aspects. One is the method of modelling mass 3D human, and the other is the way of individual behaviour visualization. Surface model is the main method for modelling 3D human. The main process of it as follows: create 3D templates according to the feature of different type people first, then process the template at geometric level to form virtual individual with different appearance shapes. Human behaviour includes general behaviour and advanced behaviour. General behaviour mainly refers to human body movement and has nothing to do with intelligence activities. Advanced behaviour refers to behaviours related to intellectual activities, such as facial expressions and gestures. Furthermore, to study the spatiotemporal behaviour of human, spatiotemporal path expressions and visualization also have become an important component of human visualization researching.

\subsection{Collaborative environment}

With data environment, model environment and expression environment, the key of collaborative environment in building fire scene VGE system is focus on the collaboration between virtual space environment in computer and fire scene in real world. And with virtual geographic experiments designed, parallel control and management of building fire scenes can be conducted also.

The way of collaboration in building fire scene includes two. First, with virtual reality devices (e.g., VR helmet, 3D VR glasses), individual in real world can enter virtual building fire scene in the form of avatar. This method provides immersive experience for user, allowing user to feel the presence of a real fire scene. The building fire scene VGE system can generate feedback (such as movement of virtual characters) according to user input (such as walking or stopping), and collaborative sensing and cooperative interaction for individuals can be provided also. Second, collaborative analysis and decisionmaking based on dy namic data input form real world. At present the spatiotemporal location of individual and the environment parameters (e.g., temperature, smoke concentration) in indoor can be dynamically obtained based on WSN (Liu, 2016) . Realtime dynamic data can access the building fire scene VGE system directly. The decision-maker can then command firefighting more effectively and refines the evacuation schedule according to the data accessed. According to the feedback from the real environment, the decisions can be adjusted dy namically, and the intelligent response to the building fire scene can be formed. Besides that, with virtual conference system, which uses audio and video equipment, communications and other tools to provide face-to-face communications, can be used to collaboration discussion and analy sis also.

\section{CONCLUSIONS}

Combined with the requirements of emergency management and decision-making, the modelling technology of building fire scene VGE system was discussed in this paper. The modelling elements of building fire scene and the four environments of the building fire scene VGE system was analysed, and the research key, the technology related was given a detail description. Different from other building fire research, a comprehensive model, building fire scene model, which contains fire event, building space environment, indoor crowd and indoor FES, was advanced in this paper, and the four elements can be modelled and analysed unified, which can provide more intelligent decision support for fire emergency management.

With the rapid development of computer and communication technology, building fire scene data acquisition methods are increasingly. This also provides a more solid foundation for building fire scene VGE system. This paper focuses on the modelling technology researching, the methods of building fire scene data acquisition and processing, and the way of access the data into building fire scene VGE system are not considered in this paper. In addition, the functions of building fire scene VGE system with the data input and the requirement of emergency management are required to design in the further research.

\section{ACKNOWLEDGEMENTS}

This work was supported by National Natural Science Foundation of China (41571387); Tianjin Research Program of Application Foundation and Advanced Technology (14JCQNJC07900); Tianjin Science and Technology Planning Project (15ZCZDSF00390); the Innovation Foundation of Tianjin Normal University (043-135202XC1606, 52XC1606).

\section{REFERENCES}

Cha, M., Han, S., Lee, J., et al., 2012. A virtual reality based fire training simulator integrated with fire dy namics data. Fire Safety Journal, 50(3), pp. 12-24.

Chow, W., 1996. Simulation of tunnel fires using a zone model. Tunnelling and Underground Space Technology, 11(2), pp. 221236.

Dimy adi, J., Spearpoint, M., Amor, R., 2008. Sharing building information using the IFC data model for FDS fire simulation. Fire Safety Science, 9(9), pp. 1329-1340.

Fan, W., Zhong, M., 2000. Review On Modeling Of Fire Physics \& Risk Assessment. Fire Safety Science, 4, pp. 165-178.

Forney, G., Mcgrattan, K., 2004. User's Guide for Smokeview Version4: A Tool for Visualizing Fire Dynamics Simulation Data. US Department of Commerce, National Institute of Standards and Technology.

Gunduz, M., Isikdag, U., Basaraner, M., 2016. A Review of Recent Research in Indoor Modelling \& Mapping. In: The International Archives of the Photogrammetry, Remote Sensing and Spatial Information Sciences, XLI-B4, pp. 289-294.

Hajibabai, L., Delavar, M., Malek, M., et al., 2007. Agent-based simulation of spatial cognition and wayfinding in building fire emergency evacuation. Geomatics solutions for disaster management. Springer, pp. 255-270. 
Hartzell, G., Emmons, H., 1988. The fractional effective dose model for assessment of toxic hazards in fires. Journal of fire sciences, 6(5), pp. 356-362.

Hasofer, A., Beck, V., Bennetts, I., 2006. Risk analysis in building fire safety engineering. Routledge

Hong, S., Jung. J., Kim, S., et al., 2013. Semi-Automatic Method for Constructing 2D and 3D Indoor GIS Maps based on Point Clouds from Terrestrial LiDAR. Journal of Korean Society for Geospatial Information System, 21(2), pp. 99-105.

Lin, H., Zhu, J., Gong, J., et al., 2010. A grid-based collaborative virtual geographic environment for the planning of silt dam systems. International Journal of Geographical Information Science, 24(4), pp. 607-621.

Isikdag, U., Underwood, J., Aouad, G., 2008. An investigation into the applicability of building information models in geospatial environment in support of site selection and fire response management processes. Advanced engineering informatics, 22(4), pp. 504-519.

Kim, J., Yoo, S., Li, K., 2014. Integrating IndoorGML and City GML for indoor space. International Symposium on Web and Wireless Geographical Information Systems, 8470, pp. 184196.

Kobes, M., Helsloot, I., De, V., et al., 2010. Building safety and human behaviour in fire: A literature review. Fire Safety Journal, 45(1), pp. 1-11.

L. G., 2011. Geographic analysis-oriented virtual geographic environment: framework, structure and functions. Science China Earth Sciences, 54(5), pp. 733.

Li, Y., Gong, J., Liu, H., et al., 2015. Real-time flood simulations using CA model driven by dynamic observation data. International Journal of Geographical Information Science, 29(4), pp. 523-535.

Lin, H., Chen, M., Lu, G., et al., 2013. Virtual geographic environments (VGEs): a new generation of geographic analysis tool. Earth-Science Reviews, 126, pp. 74-84.

Lin, H., Zhu, Q., 2005, Virtual geographic environments. CRC Press, Florida.

Liu, C., Gu, Y., 2016. Research on indoor fire location scheme of RFID based on WiFi. Nicograph International (NicoInt), pp. 116-119.

Mcgrattan, K., Hostikka, S., Mcdermott, R., et al., 2013. Fire dynamics simulator user's guide. NIST special publication, 1019(6thEdition).

Shi, J., Ren, A., Chen, C., 2009. Agent-based evacuation model of large public buildings under fire conditions. Automation in Construction, 18(3), pp. 338-347.
Song, Y, Niu, L., He, L., et al., 2016. A grid-based graph data model for pedestrian route analysis in a micro-spatial environment. International Journal of Automation and Computing, 13(3), pp. 296-304.

Song, Y., Gong, J., Niu, L., et al., 2013. A grid-based spatial data model for the simulation and analy sis of individual behaviours in micro-spatial environments. Simulation Modelling Practice and Theory, 38, pp. 58-68.

Song, Y., Gong. J., Li, Y., et al., 2013. Crowd evacuation simulation for bioterrorism in micro-spatial environments based on virtual geographic environments. Safety science, 53(2), pp. 105-113.

Spearpoint, M., 2007. Transfer of architectural data from the IFC building product model to a fire simulation software tool. Journal of Fire Protection Engineering, 17(4), pp. 271-292.

Stec, A., Hull, T., 2011. Assessment of the fire toxicity of building insulation materials. Energy and Buildings, 43(2), pp. 498-506.

Stollard, P., 2014. Fire from First Principles: A Design Guide to International Building Fire Safety. Routledge

Tang, F., Ren, A., 2008. Agent-based evacuation model incorporating fire scene and building geometry. Tsinghua Science \& Technology, 13(5), pp. 708-714.

Tang, F., Ren, A., 2012. GIS-based 3D evacuation simulation for indoor fire. Building and Environment, 49, pp. 193-202.

Thalmann, D., 2007. Crowd simulation. Wiley Online Library.

Wang, B., Li, H., Rezgui, Y., et al., 2014. BIM based virtual environment for fire emergency evacuation. The Scientific World Journal, 2014, pp. 1-22

Wu, C., Chen, L., 2012. 3D spatial information for fire-fighting search and rescue route analysis within buildings. Fire Safety Journal, 48(1), pp. 21-29.

Yin, R., Chow, W., 2002. Building fire simulation with a field model based on large eddy simulation. Architectural Science Review, 45(2), pp, 145-153.

Zhu, Q., Hu, M., Xu, W., et al., 2014. 3D building information model for facilitating dy namic analy sis of indoor fire emergency. Geomatics and Information Science of Wuhan University, 39(7), pp. 762-766. 